\title{
Properties of Erbium and Ytterbium Doped Gallium Nitride Layers Fabricated by Magnetron Sputtering
}

\author{
V. Prajzler, Z. Burian, I. Hüttel, J. Špirková, J. Hamáček, J. Oswald, J. Zavadil, V. Peřina
}

We report about some properties of erbium and erbium/ytterbium doped gallium nitride (GaN) layers fabricated by magnetron sputtering on silicon, quartz and Corning glass substrates. For fabricating GaN layers two types of targets were used-gallium in a stainless steel cup and a $\mathrm{Ga}_{2} \mathrm{O}_{3}$ target. Deposition was carried out in the Ar $+\mathrm{N}_{2}$ gas mixture. For erbium and ytterbium doping into GaN layers, erbium metallic powder and ytterbium powder or $\mathrm{Er}_{2} \mathrm{O}_{3}$ and $\mathrm{Yb}_{2} \mathrm{O}_{3}$ pellets were laid on the top of the target. The samples were characterized by X-ray diffraction (XRD), photoluminescence spectra and nuclear analytical methods. While the use of a metallic gallium target ensured the deposition of well-developed polycrystalline layers, the use of gallium oxide target provided GaN films with poorly developed crystals. Both approaches enabled doping with erbium and ytterbium ions during deposition, and typical emission at 1530 nm due to the Er ${ }^{3+}$ intra-4f ${ }^{4} I_{13 / 2} \rightarrow{ }^{4} I_{15 / 2}$ transition was observed.

Keywords: Gallium nitride, Erbium, Ytterbium, magnetron sputtering, photoluminescence.

\section{Introduction}

Gallium nitride ( $\mathrm{GaN}$ ) has become one of the most promising wide band gap $(3.4 \mathrm{eV})$ direct semiconductor materials for utilization in high power and high frequency transistors, solid state photo detectors and high brightness blue light emitting diodes (LEDs), laser diodes (LDs) and full colour flat panel displays [1], [2]. $\mathrm{Er}^{3+}$-doped optical materials are candidates for fabrication of optical amplifiers and lasers operating at $1550 \mathrm{~nm}$ [3] due to the $\mathrm{Er}^{3+}$ intra-4f emission, which corresponds to the ${ }^{4} \mathrm{I}_{13 / 2} \rightarrow{ }^{4} \mathrm{I}_{15 / 2}$ transition. This wavelength is commonly used in telecommunication systems due to the fact that it corresponds to a low loss window of silica based optical fibers.

Erbium doped amplifiers are usually optically pumped by a source operating at $1480 \mathrm{~nm}$ or $980 \mathrm{~nm}$. When only $\mathrm{Er}^{3+}$ ions are present in short waveguides, optical pumping at $980 \mathrm{~nm}$ is not sufficiently efficient, because the $\mathrm{Er}^{3+}$ absorption cross-section at this wavelength is not very good. This problem can be overcome by adding $\mathrm{Yb}^{3+}$, as its ${ }^{2} \mathrm{~F}_{5 / 2} \rightarrow{ }^{2} \mathrm{~F}_{7 / 2}$ transition is approximately ten times stronger than that of ${ }^{4} \mathrm{I}_{13 / 2} \rightarrow{ }^{4} \mathrm{I}_{15 / 2}$ [4], [5]. The Basic schematic energy levels and laser transitions of $\mathrm{Er}^{3+}$ and $\mathrm{Yb}^{3+}$ are shown in Fig. 1.

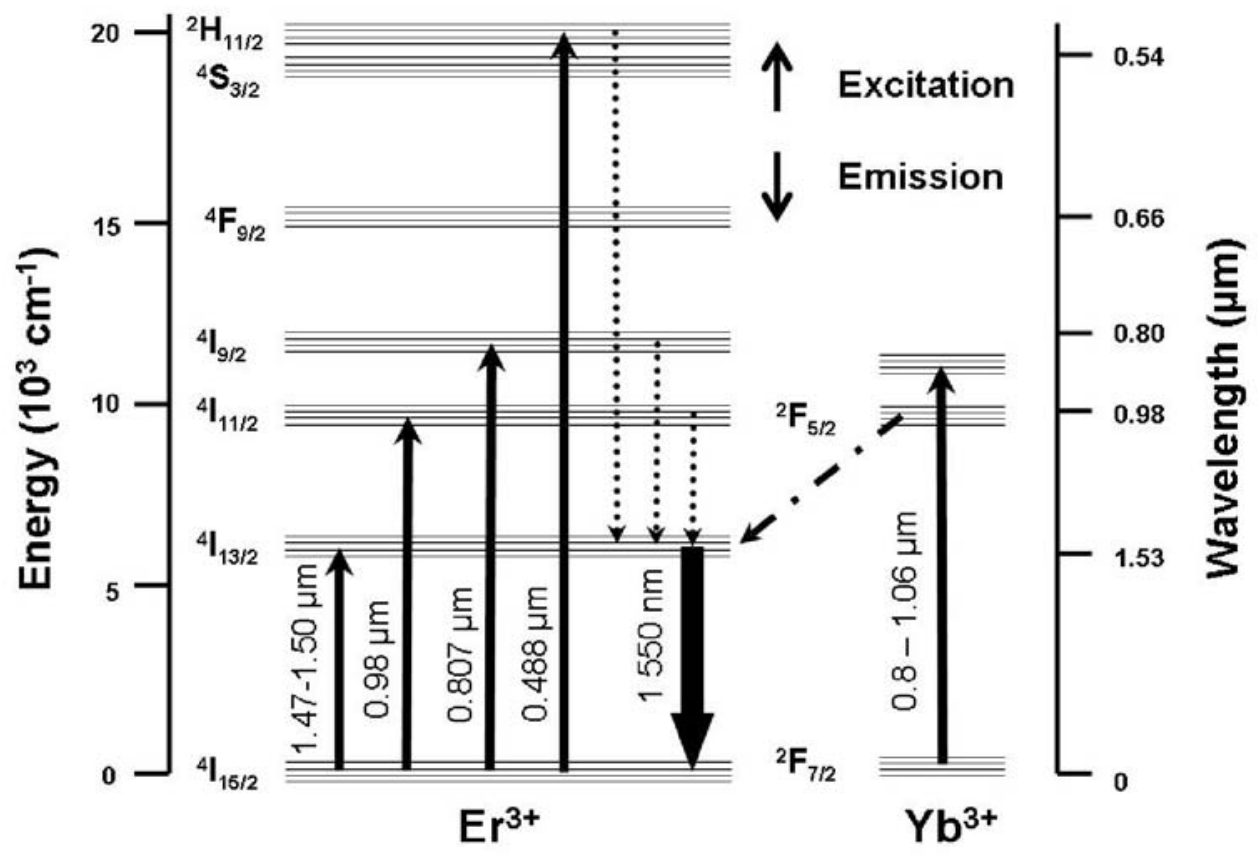

Fig. 1: Schematic energy levels and laser transitions of $\mathrm{Er}^{3+}$ and $\mathrm{Yb}^{3+}$ ions 
It was previously shown in [6] that thermal quenching in $\mathrm{Er}^{3+}$-doped semiconductors decreases with increasing band gap. Therefore, wide-band gap semiconductors such as GaN are attractive hosts for $\mathrm{Er}^{3+}$ and $\mathrm{Yb}^{3+}$ ions (RE ions).

GaN layers are usually grown by epitaxy methods such as Metal Organic Chemical Vapor Deposition (MOCVD) and Molecular Beam Epitaxy (MBE) [7], [8]. Epitaxy methods such as Hydride Vapor Phase Epitaxy (HVPE) and Liquid Phase Epitaxy (LPE) [9], [10] are used for fabricating of free standing GaN substrates. To obtain GaN layers doped with erbium and ytterbium ions, two procedures are basically available. The first procedure involves fabricating GaN layers and then doping them by ion implantation [11], [12]. The second way involves doping the GaN layers by erbium and ytterbium ions during the deposition process [13], [14]. RE-doped GaN layers fabricated by the epitaxy method are of high quality; however, the deposition process is rather complicated (for GaN fabricated by MOCVD a toxic precursor is needed, and for GaN fabricated by MBE an ultrahigh-vacuum chamber must be applied).

Instead of these rather complicated methods an easier approach to GaN fabrication is now being investigated. Yang et al. in 2003 already managed to fabricate high quality GaN layers [15] by using magnetron sputtering. Their GaN samples exhibited luminescence at $354 \mathrm{~nm}$ wavelength at room temperature. Erbium and ytterbium can easily be doped into the deposited GaN layers in the course of the sputtering process [16]. Moreover, sputter deposition is relatively inexpensive and it is ideal for covering a large area.

\section{Experiment}

\subsection{Fabrication of the samples}

The GaN samples were fabricated by radio frequency (RF) magnetron sputtering (Balzers Pfeiffer PLS 160) on silicon, quartz or Corning glass. Before deposition, the substrates were cleaned by a standard cleaning procedure. The sputtering experimental set-up is shown in Fig. 2. We used two types of target: Ga target and $\mathrm{Ga}_{2} \mathrm{O}_{3}$ target. Because of its very low

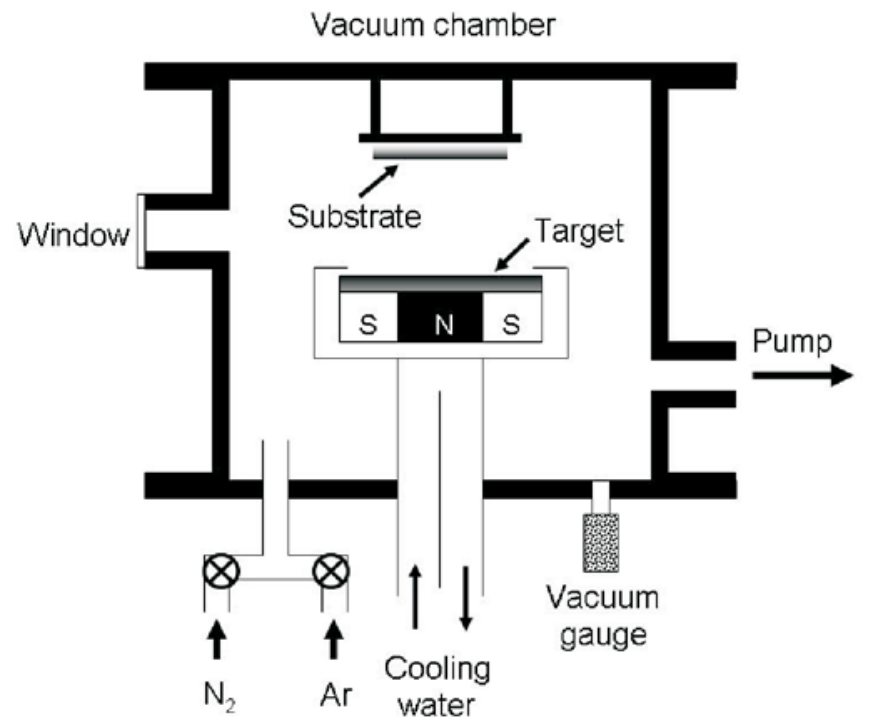

Fig. 2: Schema of the planar magnetron-sputtering set-up used for deposition of $\mathrm{GaN}$ layers melting point $\left(29.78^{\circ} \mathrm{C}\right)$, gallium cannot be used directly as a target, so we had to pour it into a stainless steel crucible. Another way is to use $\mathrm{Ga}_{2} \mathrm{O}_{3}$ target, as already reported in [17]. This would satisfactorily solve the problem arising from the low melting point of gallium, as $\mathrm{Ga}_{2} \mathrm{O}_{3}$ melts at about $1600{ }^{\circ} \mathrm{C}$. In our experiments we sintered $\mathrm{Ga}_{2} \mathrm{O}_{3}$ powder (Sigma-Aldrich) to form a target $5 \mathrm{~cm}$ diameter.

Typical deposition parameters were: temperature $300 \mathrm{~K}$, time $60 \mathrm{~min}$, nitrogen-argon ratio $3: 7$, power $50 \mathrm{~W}$. The apparatus was evacuated before each experiment below $0.01 \mathrm{~Pa}$, and deposition was done at total gas pressure 3.4 Pa. The further details of the fabrication process are given in Table 1 . Typical thickness of the deposited layers was 0.5 to $3.2 \mu \mathrm{m}$, depending on the time of deposition.

For erbium doping into gallium nitride layers, the Er metallic powder and $\mathrm{Yb}$ powder were laid on the top of gallium targets, or, Er metallic powder and $\mathrm{Yb}$ powder or $\mathrm{Er}_{2} \mathrm{O}_{3}$ and $\mathrm{Yb}_{2} \mathrm{O}_{3}$ pellets 5 or $10 \mathrm{~mm}$ in diameter were put on top of the $\mathrm{Ga}_{2} \mathrm{O}_{3}$ targets. The $\mathrm{Er}_{2} \mathrm{O}_{3}$ and $\mathrm{Yb}_{2} \mathrm{O}_{3}$ pellets were fabricated by pressing $\mathrm{Er}_{2} \mathrm{O}_{3}$ and $\mathrm{Yb}_{2} \mathrm{O}_{3}$ powder (Sigma-Aldrich).

Table 1: Deposition parameters for Er/Yb:GaN fabrication

\begin{tabular}{|c|c|c|}
\hline \multicolumn{2}{|l|}{ Target } & $\mathrm{Ga}, \mathrm{Ga}_{2} \mathrm{O}_{3}$ \\
\hline \multicolumn{2}{|c|}{ Power (13.56 MHz) } & $50 \mathrm{~W}$ \\
\hline \multicolumn{2}{|c|}{ Gas precursor (purity $99.999 \%$ ) } & mixture $\mathrm{N}_{2} / \mathrm{Ar}(3: 7)$ \\
\hline \multicolumn{2}{|c|}{ Total gas pressure } & $3.4 \mathrm{~Pa}$ \\
\hline \multicolumn{2}{|c|}{ Target substrate distance } & $3.7 \mathrm{~cm}$ \\
\hline \multicolumn{2}{|c|}{ Deposition time } & $1-4 \mathrm{hr}$ \\
\hline \multicolumn{2}{|c|}{ Deposition temperature } & $300 \mathrm{~K}$ \\
\hline \multirow[b]{2}{*}{ RE doping } & using pellets & $\mathrm{Er}_{2} \mathrm{O}_{3}, \mathrm{Yb}_{2} \mathrm{O}_{3}$ \\
\hline & using powder & $\begin{array}{l}\text { Er metallic powder, } \\
\text { Yb powder }\end{array}$ \\
\hline
\end{tabular}

\subsection{Measurement}

The structure of the deposited GaN layers was studied by XRD (X-ray diffraction). The compositions of the samples were determined with the use of nuclear chemical analysis (Rutherford Backscattering Spectroscopy (RBS) and Elastic Recoil Detection Analysis (ERDA)). The GaN stoichiometry and the $\mathrm{O}$ admixture amount was checked by RBS using $2.4 \mathrm{MeV}$ protons. For this energy the non-Rutherford cross-section for $\mathrm{N}$ and $\mathrm{O}$ is sufficiently enhanced to obtain satisfactory sensitivity. The amounts of the erbium and ytterbium dopants were checked by RBS with both $2.4 \mathrm{MeV}$ protons and 2.2 MeV alpha particles. The areas in the spectra above the surface of the Ga energy edge enabled us to determine the RE concentrations up to a depth of 600 and $240 \mathrm{~nm}$ from the GaN surface for $2.4 \mathrm{MeV}$ protons and 2.2 MeV alpha particles, respectively. The $\mathrm{H}$ impurity was checked by ERDA with the $2.7 \mathrm{MeV}$ alpha particles. The evaluations of the RBS and ERDA spectra were done by GISA3 [18] and SIMNRA [19] code, respectively.

The transmission spectra of the samples in the spectral region from $400 \mathrm{~nm}$ to $1000 \mathrm{~nm}$ at room temperature were also taken. For this purpose, a tungsten lamp and MDR 23 
monochromator were used as light sources, and the light transmitted through the samples was detected by a pyrodetector. The photoluminescence measurement was carried out at three excitation wavelengths:

- Ar laser ILA-120 operating at $\lambda_{\mathrm{ex}}=488 \mathrm{~nm}, E_{\mathrm{ex}}=100 \mathrm{~mW}$,

- Ar lasers operating at $\lambda_{\mathrm{ex}}=514.5 \mathrm{~nm}, E_{\mathrm{ex}}=300 \mathrm{~mW}$,

- Semiconductor laser P4300 operating at $\lambda_{\mathrm{ex}}=980 \mathrm{~nm}$, $E_{\mathrm{ex}}=500 \mathrm{~mW}$.

An FEU62 photocell was used to detect the wavelength from 500 to $1000 \mathrm{~nm}$, while a Ge detector was used for the wavelengths from $1000 \mathrm{~nm}$ to $1600 \mathrm{~nm}$. The reference chopper frequency was $75 \mathrm{~Hz}$. All the luminescence measurements were performed at room temperature.

\section{Result and Discussion}

The structure of the deposited GaN thin films was studied by XRD (X-ray diffraction), and the results have already been given in [20]. It was shown that the GaN structures depended on the type of the target and temperature used for the deposition. GaN films grown using the $\mathrm{Ga}_{2} \mathrm{O}_{3}$ target at room temperature had an amorphous structure, while GaN films fabricated using the Ga target at room temperature had polycrystalline structure (According to the literature, GaN layers fabricated at an elevated temperature (above $800^{\circ} \mathrm{C}$ ) can have a single crystalline structure [21]).

The exact composition of the deposited GaN layers was determined by nuclear analytical methods (RBS, ERDA). The typical RBS spectrum of an erbium doped $\mathrm{GaN}$ layer is shown in Fig. 3.

The analyses proved that the samples contained gallium, nitrogen, oxygen, argon, hydrogen and erbium and/or ytterbium ions (see Table 2). The amount of incorporated $\mathrm{Er}^{3+}$ and $\mathrm{Yb}^{3+}$ ions differed depending on the area of the target covered by the erbium and ytterbium co-dopant, and also on the erosion area represented by the part of the surface target

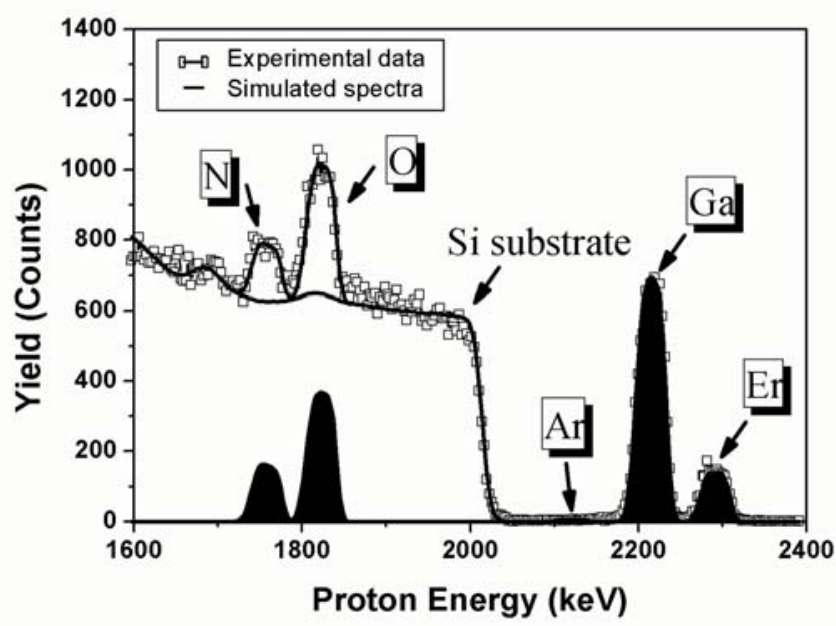

Fig. 3: RBS spectrum of Er-doped GaN containing 1.3 at \% Er

Table 2: Composition of RE-doped GaN samples as determined by Rutherford Backscattering Analysis and Elastic Recoil Detection Analysis

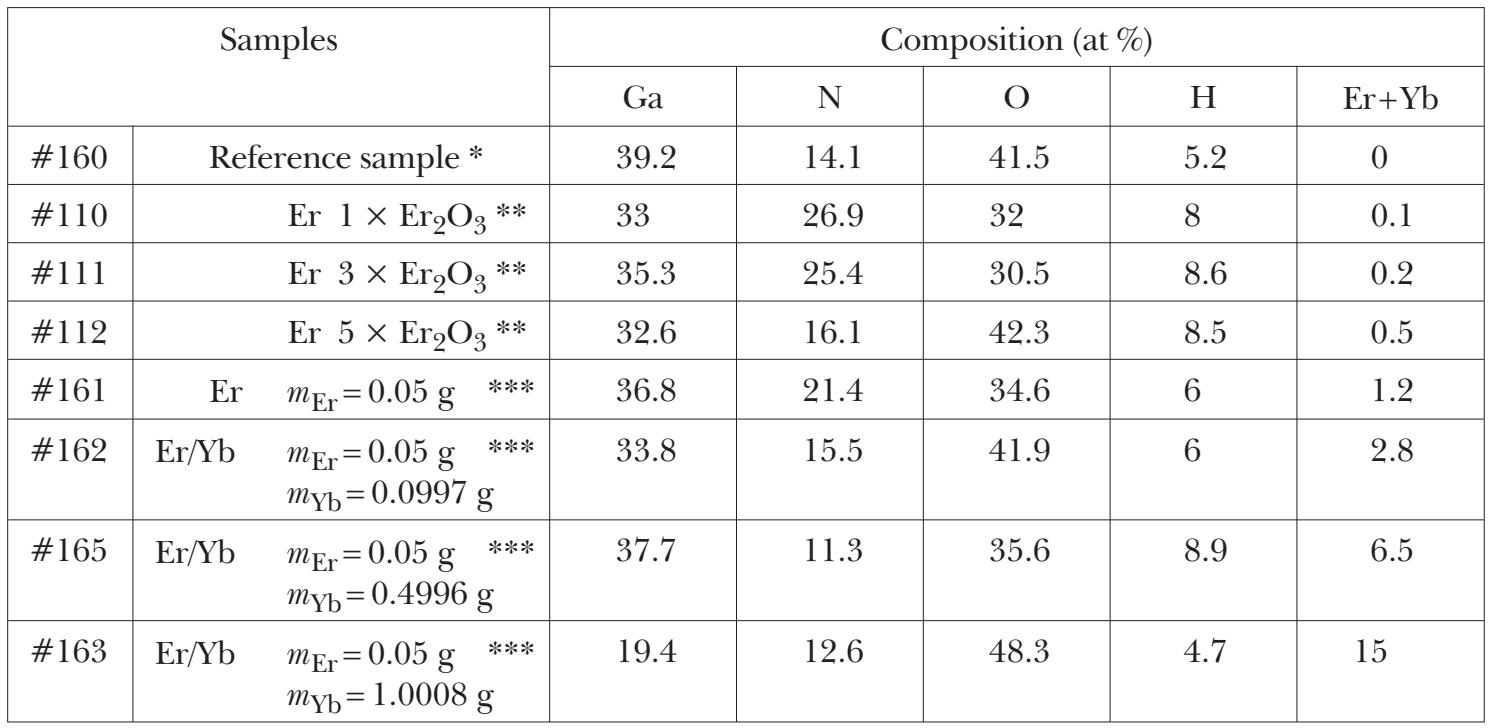

* Sample without $\mathrm{Er}+\mathrm{Yb}$ doping, ** number of $\mathrm{Er}_{2} \mathrm{O}_{3}$ pellets ( $5 \mathrm{~mm}$ diameter) put on top of the $\mathrm{Ga}_{2} \mathrm{O}_{3}$ target, *** weight of Er or $\mathrm{Yb}$ powder put on top of the $\mathrm{Ga}_{2} \mathrm{O}_{3}$ target 


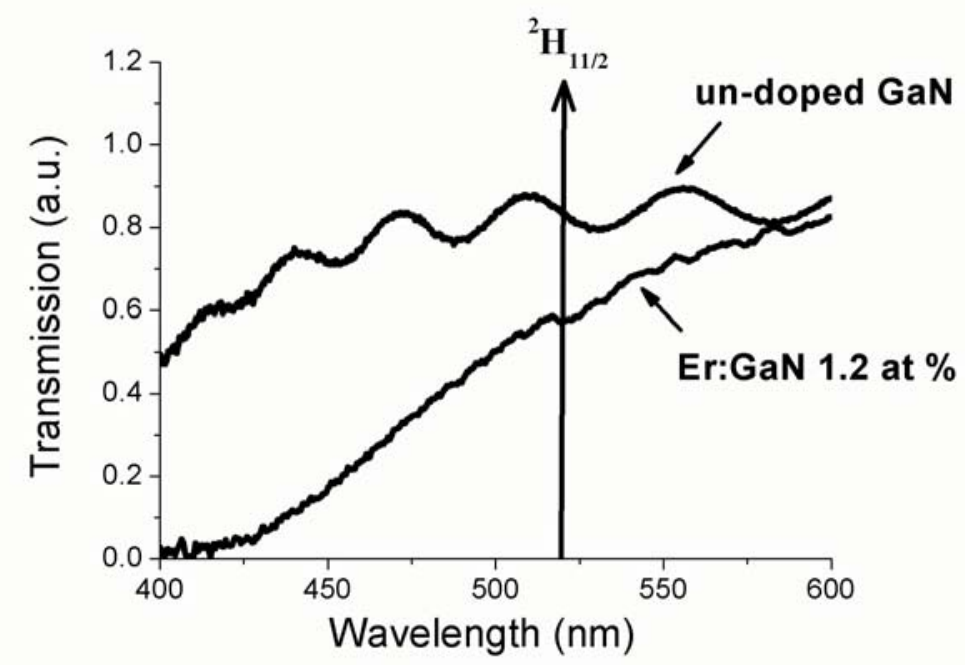

Fig. 4: Transmission spectra of the Er:GaN sample

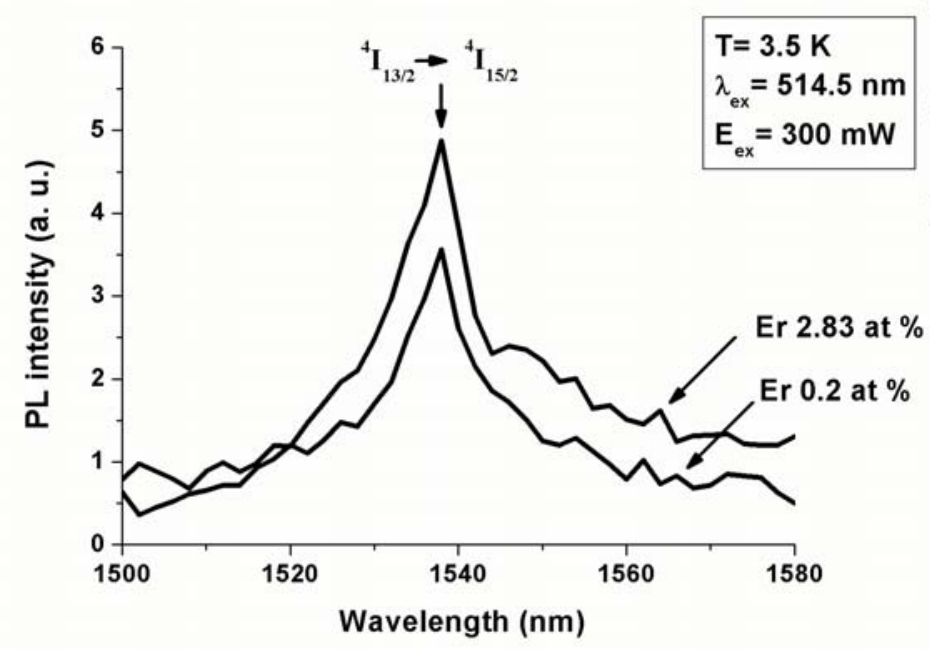

Fig. 5: PL spectra of the Er-doped GaN layers fabricated by magnetron sputtering using a Ga target and erbium metallic powder laid on top of the target

covered by erbium and ytterbium. As Er and $\mathrm{Yb}$ have very close, atomic weight values these two elements cannot be distinguished in the RBS spectra, so that only the sum of the two elements can be obtained. According to Table 2, a significant amount of hydrogen is found in GaN films, with the relative concentrations ranging between 4 and 9 at \%. This unintended presence of hydrogen in the samples is probably a consequence of the residual contamination of the $\mathrm{Ar}$ and/or

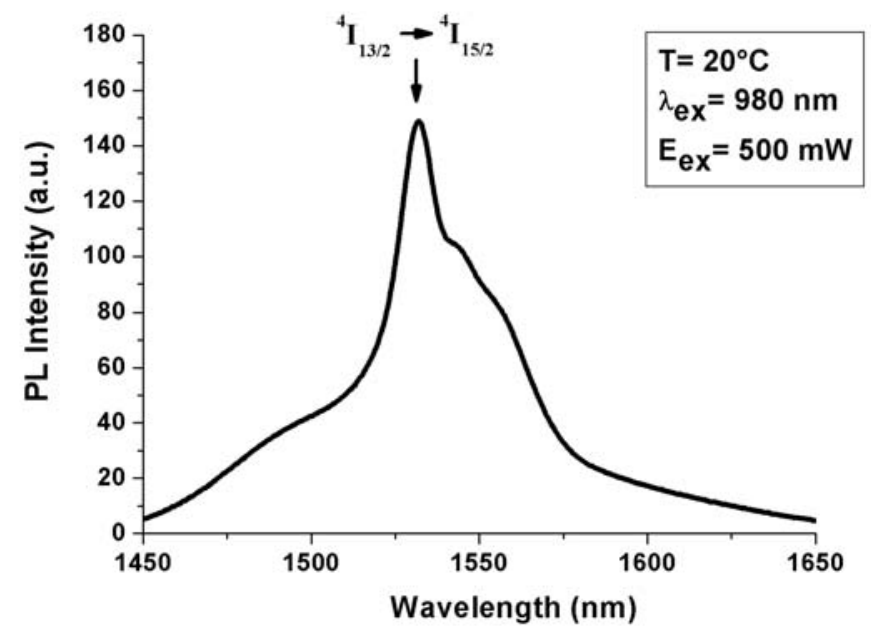

Fig. 6: PL spectra of an Er-doped GaN layer fabricated by magnetron sputtering using the gallium oxide target and two pellets (5 mm diameter) of erbium oxide laid on the top of the target 


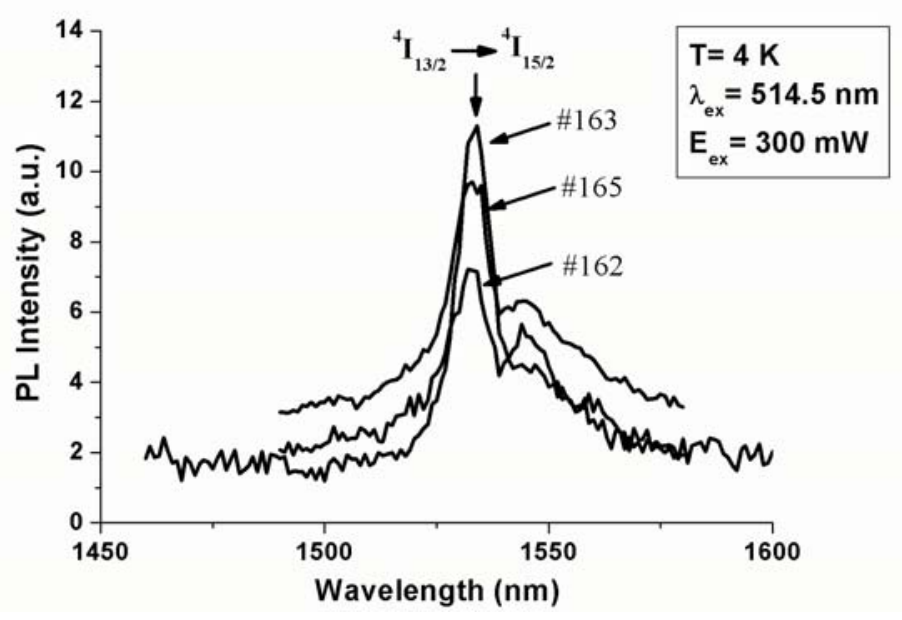

Fig. 7: PL spectra of Er/Yb-doped GaN layers fabricated by magnetron sputtering using erbium and ytterbium powder laid onto a $\mathrm{Ga}_{2} \mathrm{O}_{3}$ target

$\mathrm{N}_{2}$ gases that are employed. They contained approximately 5 ppm of hydrogen [22]. The GaN samples also contained a small amount of argon (around the detection limit 1 at \%), due to the argon atmosphere used during deposition.

Fig. 4 compares the transmission spectra of the sputtered GaN doped with 1.2 at. \% of erbium with the un-doped GaN sample. The arrows in the figure mark the strongest transitions of the $\mathrm{Er}^{3+}$ ions $\left({ }^{2} \mathrm{H}_{11 / 2}\right)$. However, we observed only a weak peak attributed to the $\mathrm{Er}^{3+}$ transition. We did not observe any transition of the $\mathrm{Yb}^{3+}$ ions at $980 \mathrm{~nm}\left({ }^{2} \mathrm{~F}_{5 / 2}\right)$ with the erbium doped $\mathrm{GaN}$ layers co-doped by $\mathrm{Yb}^{3+}$ ions, probably because the absorption coefficients for ytterbium ions are very low and/or the deposited layers are rather thin.

The photoluminescence spectrum of the $\mathrm{Er}^{3+}$ doped GaN layers fabricated using a Ga target excited at $\lambda_{\text {ex }}=514.5 \mathrm{~nm}$ at a temperature of $4 \mathrm{~K}$ is given in Fig. 5. The figure shows typical photoluminescence bands attributed to the erbium transition ${ }^{4} \mathrm{I}_{13 / 2} \rightarrow{ }^{4} \mathrm{I}_{15 / 2}$. We obtained the best result for the GaN sample containing about 2.83 at \% of erbium.

Fig. 6 shows the photoluminescence spectra of a GaN layer doped by $\mathrm{Er}^{3+}$ fabricated using the $\mathrm{Ga}_{2} \mathrm{O}_{3}$ target and
$\mathrm{Er}_{2} \mathrm{O}_{3}$ pellets laid on top of the target, obtained by using optical pumping at $980 \mathrm{~nm}$ at room temperature.

Fig.7 shows the $1530 \mathrm{~nm}$ region of the photoluminescence spectra of the $\mathrm{Er}^{3+} / \mathrm{Yb}^{3+}$ containing GaN samples fabricated by doping from erbium-ytterbium powder put onto a $\mathrm{Ga}_{2} \mathrm{O}_{3}$ target, excited by an Ar laser $\left(\lambda_{\text {ex }}=514.5 \mathrm{~nm}\right.$, temperature 4 $\mathrm{K})$. The typical photoluminescence bands attributed to erbium $4 \mathrm{I} 13 / 2 \rightarrow 4 \mathrm{I} 15 / 2$ increased in intensity with increasing ytterbium content (for details, see Table 2). The best results were obtained when we laid $0.05 \mathrm{~g}$ of erbium metallic powder and $1 \mathrm{~g}$ ytterbium powder onto the target.

Fig. 8 shows the same photoluminescence spectra as Fig. 7, but now obtained by optical pumping at $980 \mathrm{~nm}$ at room temperature, which indicates better quality of the samples.

\section{Conclusion}

Two basic approaches for RF magnetron sputtering of $\mathrm{GaN}$ thin films have been presented. The first one, utilizing a metallic gallium target, provides deposition of well-developed

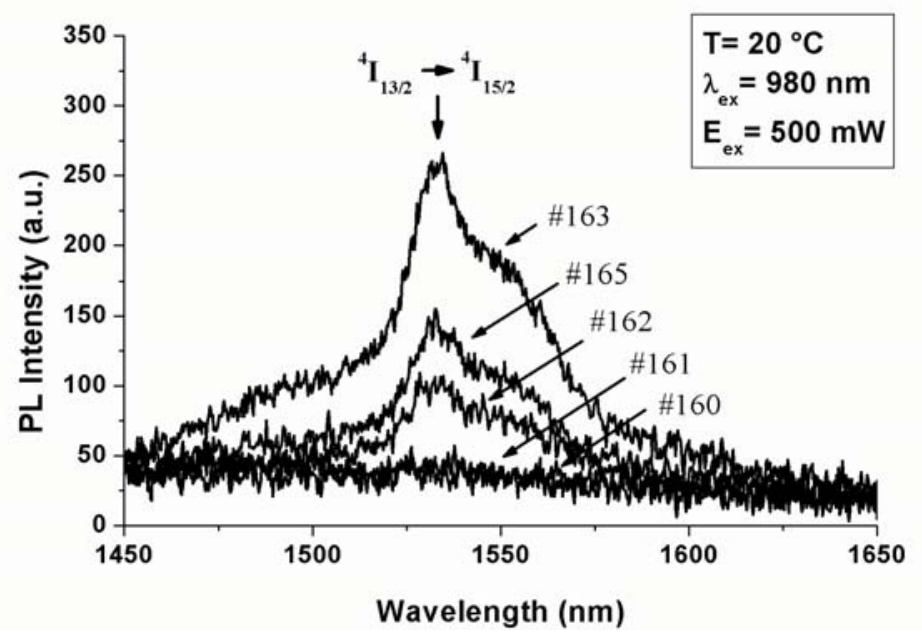

Fig. 8: PL spectra of $\mathrm{Er} / \mathrm{Yb}$-doped GaN layers fabricated by magnetron sputtering using erbium and ytterbium powder laid onto a $\mathrm{Ga}_{2} \mathrm{O}_{3}$ target 
polycrystalline layers. The second, using a gallium oxide target, resulted in almost amorphous GaN films with poorly developed crystals. The $\mathrm{Er} / \mathrm{Yb}$ doped GaN samples exhibited the typical emission at $1530 \mathrm{~nm}$ due to the $\mathrm{Er}^{3+}$ intra-4f ${ }^{4} \mathrm{I}_{13 / 2} \rightarrow{ }^{4} \mathrm{I}_{15 / 2}$ transition even pumped at $980 \mathrm{~nm}$ at room temperature. The layers co-doped with $\mathrm{Yb}$ ions revealed increased intensity of luminescence.

Thus the possibility of fabrication of erbium and ytterbium ions containing GaN films by magnetron sputtering was demonstrated.

\section{Acknowledgments}

Our research has been supported by the Grant Agency of the Czech Republic (grant No. 102/06/0424), by research program MSM6840770014 of the Czech Technical University in Prague and by Ministry of Education, Youth and Sports of the Czech Republic (grant No. LC6041). We specially thank Petr Bak for technical support and Bohumír Dvořák for providing the $\mathrm{Er}_{2} \mathrm{O}_{3}$ and $\mathrm{Yb}_{2} \mathrm{O}_{3}$ pellets.

\section{References}

[1] Morkoc, H., Strite, S., Gao, G. B., Lin, M. E., Sverdlov, B., Burns, M.: "Large-Band-Gap SiC, III-V Nitride, and II-VI ZnSe-Based Semiconductor-Device Technologies." Journal of Applied Physics, Vol. 76 (1994), No. 3, p. 1363-1398.

[2] Steckl, A. J., Heikenfeld, J. C., Lee, D. S., Garter, M. J., Baker, C. C., Wang, Y. Q., Jones, R.: "Rare-Earth-Doped GaN: Growth, Properties, and Fabrication of Electroluminescent Devices." IEEE Journal of Selected Topics in Quantum Electronics, Vol. 8 (2002), No. 4, p. 749-766.

[3] Kik, P. G., Polman, A.: "Erbium Doped Optical-Waveguide Amplifiers on Silicon.” MRS Bulletin, Vol. 23 (1998), No. 4, p. $48-54$.

[4] Chryssou, C.E. - Di Pasquale, F. - Pitt, C.W.: "Improved Gain Performance in $\mathrm{Yb}^{3+}$-Sensitized $\mathrm{Er}^{3+}$-Doped Alumina $\left(\mathrm{Al}_{2} \mathrm{O}_{3}\right)$ Channel Optical Waveguide Amplifiers." Journal of Lightwave Technology, Vol. 19 (2001), No. 3, p. 345-349.

[5] Hubner, J., Guldberg-Kjaer, S., Dyngaard, M., Shen, Y., Thomsen, C. L., Balslev, S., Jensen, C., Zauner, D., Feuchter, T.: "Planar Er- and Yb-Doped Amplifiers and Lasers." Applied Physics B-Lasers and Optics, Vol. 73 (2001), No. 5-6, p. 435-438.

[6] Favennec, P. N., Lharidon, H., Salvi, M., Moutonnet, D., Leguillou, Y.: "Luminescence of Erbium Implanted in Various Semiconductors - IV-Materials, III-V-Materials and II-VI Materials.” Electronics Letters, Vol. 25 (1989), No. 11, p. 718-719.

[7] Amano, H., Sawaki, N., Akasai, I., Toyoda, Y.: "Metalorganic Vapor-Phase Epitaxial-Growth of High-Quality GaN Film Using an AlN Buffer Layer." Applied Physics Letters, Vol. 48 (1986), No. 5, p. 353-355.

[8] Doppalapudi, D., Iliopoulos, E., Basu, S. N., Moustakas T. D.: "Epitaxial Growth of Gallium Nitride Thin Films on A-Plane Sapphire by Molecular Beam Epitaxy." Journal of Applied Physics, Vol. 85 (1999), No. 7, p. 3582-3589.
[9] Molnar, R. J., Gotz, W., Romano, L. T., Johnson, M. N.: "Growth of Gallium Nitride by Hydride Vapor-Phase Epitaxy.” Journal of Crystal Growth, Vol. 178 (1997), No. 1-2, p. 147-156.

[10] Klemenz, C., Scheel, H. J.: "Crystal Growth and Liquid-Phase Epitaxy of Gallium Nitride.” Journal of Crystal Growth, Vol. 211 (2000), No. 1-4, p. 62-67.

[11] Song, S. F., Chen, W. D., Zhu, J. J., Hsu, C. C.: "Dependence of Implantation-Induced Damage with Photoluminescence Intensity in GaN:Er." Journal of Crystal Growth, Vol. 265 (2004), No. 1-2, p. 78-82.

[12] Chen, W. D., Song, S. F., Zhu, J. J., Wang, X. L., Chen, C. Y., Hsu C. C.: "Study of Infrared Luminescence from Er-Implanted GaN Films." Journal of Crystal Growth, Vol. 268 (2004), No. 3-4, p. 466-469.

[13] Hommerich, U., Nyein, E. E., Lee, D. S., Heikenfeld, J., Steckl, A. J., Zavada, J. M.: "Photoluminescence Studies of Rare Earth (Er, Eu, Tm) in Situ Doped GaN.” Materials Science and Engineering B-Solid State Materials for Advanced Technology, Vol. 105 (2003), No. 1-3, p. 91-96.

[14] Hansen, D. M., Zhang, R., Perkins, N. R., Safvi, S., Zhang, L., Bray, K. L., Kuech, T. F.: "Photoluminescence of Erbium-Implanted GaN and in Situ-Doped GaN:Er.” Applied Physics Letters, Vol. 72 (1998), No. 10, p. 1244-1246.

[15] Yang, Y. G., Ma, H. L., Xue, C. S., Hao, X. T., Zhuang, H. Z., Ma, J.: "Characterization of GaN Films Grown on Silicon (111) Substrates.” Physica B-Condensed Materials, Vol. 325 (2003), No. 1-4, p. 230-234.

[16] Kim, J. H., Shepard, N., Davidson, M. R., Holloway, P. H.: "Visible and Near Infrared Alternating Current Electroluminescence from Sputter Grown GaN Thin Films Doped with Er." Applied Physics Letters, Vol. 83 (2003), No. 21, p. 4279-4281.

[17] Yang, Y. G., Ma, H. L., Xue, C. S., Zhuang, H. Z., Hao, X. T., Ma, J., Teng, S. Y.: "Preparation and Structural Properties for GaN Films Grown on Si (111) by Annealing." Applied Surface Science, Vol. 193 (2002), No. 1-4, p. 254-260.

[18] Saarilahti, J., Rauhala, E.: "Interactive Personal-Computer Data-Analysis of Ion Backscattering Spectra." Nuclear Instruments $\mathcal{E}$ Methods in Physics Research Section B-Beam Interactions with Materials and Atoms, Vol. 64 (1992), No. 1-4, p. 734-738.

[19] Mayer, M.: Simnra Users Guide, Institute für Plasmaphysik, 1998.

[20] Prajzler, V., Schröfel, J., Hüttel, I., Špirková, J., Hamáček, J., Machovič, V., Peřina V.: Er:GaN Thin Films Fabricated by Magnetron Sputtering, In: Thin Films 2004 E Nanotech 2004 (Editors: Sam Zhang, Xianting Zeng). Singapore, Nanyang Technological University, 2004, 34-OTF-A315.

[21] Ross, J., Rubin, M.: "High-Quality GaN Grown by Reactive Sputtering." Materials Letters, Vol. 12 (1991), No. 4, p. 215-218.

[22] Zanatta, A. R., Ribeiro, C. T., Freire, F. L.: "Optoelectronic and Structural Properties of Er-Doped Sputter-Deposited Gallium-Arsenic-Nitrogen Films." Journal of Applied Physics, Vol. 90 (2001), No. 5, p. 2321-2328. 
Ing. Václav Prajzler

e-mail: xPrajzlv@feld.cvut.cz

Doc. Ing. Zdeněk Burian, CSc.

e-mail: Burian@fel.cvut.cz

Department of Microelectronics

Czech Technical University

Faculty of Electrical Engineering

Technická 2

16627 Prague, Czech Republic

Doc. Ing. Ivan Hüttel

e-mail: Ivan.Huttel@vscht.cz

RNDr. Jarmila Špirková, CSc.

e-mail: Jarmila.Spirkova@vscht.cz

Ing. Jiří Hamáček

e-mail: Jiri.Hamacek@vscht.cz

Institute of Chemical Technology

Technická 5

16627 Prague, Czech Republic
Ing. Jiří Oswald, CSc.

e-mail: Oswald@fzu.cz

Institute of Physics, Czech Academy of Sciences Cukrovarnická 10

16253 Prague, Czech Republic

RNDr. Jiří Zavadil, CSc.

e-mail: Zavadil@ure.cas.cz

Institute of Radio Engineering and Electronics Czech Academy of Sciences

Chaberská 57

18251 Prague, Czech Republic

RNDr. Vratislav Peřina, CSc.

e-mail: Perina@ujf.cas.cz

Institute of Nuclear Physics

Czech Academy of Sciences

25068 Řež near Prague, Czech Republic 